\title{
GOING FORWARD, GOING BACK: COVID PANDEMIC WHERE TO FROM HERE?
}

\author{
David S Briggs AM, Editor in Chief; Godfrey Isouard, Invited Contributing Editor
}

A decade ago, APJHM published an editorial that referenced Janus, from Roman mythology as follows:

\begin{abstract}
'Janus is the god of gates, doors, doorways, beginnings and endings', [1] and is depicted as having two faces, looking in opposite directions, looking into the future and the past. This description of Janus includes being patron of "concrete and abstract beginnings of the world, the human life, new historical ages and economical enterprises.' [1] Importantly, to the theme of this editorial, Janus was frequently utilised "to symbolise change and transitions such as the progression of past to future, of one condition to the other, of one vision to the future' . . and was 'representative of the middle ground'. [1,2]
\end{abstract}

This reference from history is an excellent descriptor of where we all find ourselves in this current Covid pandemic experience. Despite those who are unaware of or are currently challenging the importance of history, there is a strong case for us to be aware of the history of pandemics and how they were all overcome. The concept of both looking forward and looking back is a powerful metaphor to describe what should be a sensible discussion and consideration of where we might be going.

This editorial and special issue is being published because our readers have submitted an overwhelming number of articles to us for publication. It is an attempt to allow us all to hear the voices and the experience of a diverse range of health professionals across the health systems within the Asia Pacific in encountering this pandemic.

The editorial goes to the personal and professional challenges we are facing as managers and leaders in health systems and in our communities. There is a realisation that we are going to face these challenges over a longer time frame and that we will not quickly return to the past status quo. It is uncertain as to what the future might present, perhaps, an uncertain 'new normal'. This is not meant to be negative in connotation. What might be the 'new normal' could well be innovative and provide different and better ways to deliver healthcare!

The articles in this issue all give differing perspectives on how the pandemic occurred and was declared and acted on. However, It was the Australian Prime Minister who was firmly determined that we were entitled and should be informed about the event, the occurrences and the timelines of the global pandemic, so that we might learn from what had occurred, to ensure better future approaches. His leadership and that of others saw most democratically elected governments support that initiative with a review commencing.[3] A recent article describes what 'good leadership looks like during this pandemic' as requiring 'acting with urgency, communicating with transparency, responding productively to missteps and to engage in constant updating'. [4] the authors also describe depending on expert advice and elements of being inclusive, engaging and demonstrating empathy. These concepts are consistent with both the Australian and New Zealand approaches to addressing the pandemic.

The next significant Australian initiative to address the pandemic was the establishment, by the Prime Minister of a 'National Cabinet' that saw the State and Territory Premiers included in as members to address our local and national challenges. For those of you who are unfamiliar with Australia as a nation, it was established in 1901 as a Federation of States and Territories with an overarching Commonwealth government and a division powers between both major levels of government. This context tends to create unnecessary duplication of funding and 
roles with the States basically directing the public acute care sector and the Commonwealth partly funding acute care and directly funding general practice and aged care providers, both operating as independent businesses and services.

If you live in a Federation you require collaboration cooperation and shared use of resources across local, state/territory and the Commonwealth or national levels of government. This, in normal circumstances is difficult to achieve, let alone in managing and resolving a pandemic. The creation of the 'National Cabinet' inclusive of State and territory Premiers/First Ministers demonstrated inclusive leadership at the national level. It was quickly followed by the dismantling of the previously functioning Council of Australian Governments (COAG) that had responsibility for across levels of government policy making and was quickly replaced by the formation of the National Federation Reform Council to change the way governments work together.

At all times, the national and state/territory political leaderships were inclusive of chief medical officers in their public media presentations. The chief medical officers of the States and Territories are part of the Australian Health Protection Principal Committee, chaired by the Australian Chief Medical Officer, and is the key decision-making committee for emergencies. While the speed required in responding sometimes meant that health professionals and providers heard policy announcement at the same time as communities, the political and bureaucratic levels of government in Australia have been well informed during the pandemic and mostly singly purposeful in their respective decision making.

The next positive Australian approach was an obvious and intended emphasis by the collective political leadership on projecting and insisting on a public and inclusive interaction with the entire national population on an almost daily basis that was repeated on a state/territory and local government level. The message was clear simple and direct. We were encouraged more so than directed and the political leadership gave agreed messages supported by medical and scientific advice.

While some sections of the media suggested publicly that they might be considered a 'safe and trusted' sources of Covid_19 information, they were surpassed by the Prime Minister and the Australian Chief Medical Officer and the Premiers and their State Health officers and, even to the extent that local members of parliament, district police inspectors and the local mayor all replicated the Covid_19 messages at the more local level. This was consolidated by the health system with Primary Health Networks (PHNs) at the primary healthcare (PHC) level and local health districts (LHDs) at the acute care sector all contributing post Covid_19 action, education, mainstream media, and social media.

While, initially there was forecasting based on modelling, published like the climatology debate modelling on global warming, these pronunciations predicting dire consequences in Australia proved short term and substantially inaccurate and, soon dissipated.

The disappointing and recent trend in Australia at the state and territory levels, with differing perspectives of philosophy and ideology tended to see different policy making and implementation, seemingly inconsistent with the 'national cabinet' view! Consequently, we have seen some state premiers' close borders, restricting the normal movement of both trade and commerce and 'ordinary, everyday Australians' in pursuing a normal life. We have seen the 'protest movements' and the consequences that these would subsequently bring to vulnerable groups and communities generally handled differently from state to state. No doubt some will argue that these variations reflect the fine line and balance between competing interests of economic, health and the social needs of community, and nation. Judgement over time, by the electorate will determine the public view.

It is disappointing, that historical lines on a map are used in a way that diminishes us as a Nation. It should be obvious to most that one size does not fit all. It seems logical that we are Australians first and, for example, the communities of southern Queensland and the NSW northern border and the similar conurbations of Albury and Wodonga could easily stand alone as regions and states in their own right! Perhaps an agenda item for the National Federation Reform Council. It seems to make common sense to isolate and lockdown where the evidence suggests there is a problem and not lock down vast sparsely populated areas because they are part of a state or territory! This is even more so where health staff from one State or territory are denied access to their place of employment to provide health care because of a notional line on a map that denotes a state border? It raises the question as to what is an appropriate geographical scale and identity to be regarded as a State or region of Australia? 
The political and bureaucratic levels of government were careful in not 'blaming' themselves and others for poor decision making or not being prepared to act quickly enough. However, it was obvious that haste was an important factor as in the context of cruise ships, where a Special Commission of Inquiry is in process to adjudicate the disappointing context and outcomes. Returning interstate and international travellers, meatworks, some aged care facilities, hotel isolation practices all could have been better addressed and in some way are under criticism or the subject of formal Inquiries. All would be aware that responsibilities come with accountabilities and although lessons learned are important there are sometimes consequences.

The disturbing circumstances was that different states and territories had differing levels of capacity to respond and were at differing levels of responsibility in the health systems hierarchies for public health. At a National level we would want significant public health monitoring of potential infectious disease and a high-level responsiveness at the state/territory and local government levels. The inadequacies appeared obvious. It was pleasing to see that some states/territories did present a strong public health presence at both the State and regional level. In addressing future directions for healthcare organisation and delivery, policy makers would be well advised to maximise the concepts of localism and the principle of subsidiarity, where government decision making delivers services as close as possible to the people meant to receive those services and not from distant levels of government. [5] Current organisational responsibilities and arrangements, have been criticised for some time. [6] It has been obvious over a considerable period of time that the development of hospitals into large systemized health systems continues to demonstrate variable utilization and outcomes evident across the system and between States and territories. [7]

Looking further afield to other democracies of larger scale in populations and with differing political systems seems to suggest that we in Australia have done relatively well. Australians have culturally not been overstimulated by the political and bureaucratic processes and not markedly surprised by what occurs. They seem to understand that the 'public good' of services is an accepted concept for the benefit of the population and of communities. The other distinction for Australia is that not only do we have a right to vote we are in fact required to vote. As some former politicians have said of the Australian electorate, the voters generally get it right.

This is an important feature of the Australian democracy and our national identity that stands in stark contrast to the individualism and supremacy of individual rights above that of the majority community, in other countries, who have a right to vote but are not required to exercise that vote. If you think this view is unfair here, seek out the writing of ' $a$ newer chum', a newer Australian from England now embedded in Melbourne. [8] There was a mature, conforming response by most Australians to self-isolation and social distancing. A willing response to conform and at natural ease with bureaucracy.

In those countries where public policy seems to evolve from direct public engagement, talking at each other and between the individual, the media, and political interests more so than talking with each other, through the political process, we are confronted with disappointing and violent behaviours. Yes, Australians deserve commendation for the majority approach.

In other countries, notably Asian in the region we again see mostly national governments with culturally respectful populations who are used to living in close proximity but who have also placed PHC and public health at the centre of their health systems. There is little debate in those countries about the merits of wearing masks, washing hands and self-distancing. Many of them have done well and even better than those where there is a greater focus on acute care.

Ageism in a pandemic has surfaced with the aged workforce, being stood down 'so we could protect them' while those whose home is 'in residential care' becoming isolated from family and friends so 'we could protect them' and the acute care and aged care sectors having some differing views about were the aged might best be treated when acute symptoms present. There has been little discussion abought individual rights and autonomy and it is a difficult and challenging area for all. It is a conversation that needs to happen across age groups and across and between providers and employers. There are a number of us, health professionals who are suddenly being defined as aged, a notion some of us reject while we continue to lead active and fulfilling roles and lives. Perhaps, a visit to the 'EveryAgeCounts' website might be a good starting point for us all. [9] 
While the economy is being maintained in the hope that the current investments can sustain us there is an underlying need to get us all mobile and re-engaged in life. Acute care elective surgery has been on hold and some media is already pointing to surgery waiting lists extending out. At the same time the private hospital sector remains limited in activity and it seems in a viable public/private sector that government could be more concerned with using that private sector capacity to help address demand rather than channelling acute care funding through traditional geographic boundaries that can be described as historical lines on the map. Reform in the acute care sector in how capacity is used might be a way forward. In PHC there is an increased campaign to encourage patients not to remain distant from their PHC providers. At the same time there is immense interest in continued access and use of telemedicine and telehealth, particularly in rural and remote communities. There is much to be done in rural areas particularly as many of those communities are vulnerable and have poorer health outcomes. The value of $\mathrm{PHN}$ in delivering a wide range of $\mathrm{PHC}$ services is evident, they delivered well in collaboration with LHD services. These initial successes should be strengthened post Covid.

While current difficulties continue as we publish, we need to give serious consideration to where to from here! The education and professional development of health professionals in the management of health systems and in the leadership of health teams and services across traditional organisational boundaries has become paramount. Managing emergency, disasters and pandemics is new territory for many. Understanding, that these circumstances present opportunity for change and health reform should be foremost in all our minds. The potential for innovation and advancing healthcare through technology and, making new arrangements as to how we might deliver healthcare should be our focus. Australia and the Asia Pacific are well served by a collegiate approach to engaging together at the professional development level and in teaching education and research and the preferred approach has been well documented. [10] We all need to stand up and demonstrate that leadership here.

DS Briggs AM, Editor in Chief and G, Isouard, Invited Contributing Editor

\section{References}

1. Wikipedia Encyclopaedia. Janus. [Accessed: 2010 October 4.] Available from: http://en.wikipedia.org/wiki/Janus

2. Briggs, DS. (2010). Janus-like Policymakers and Health Managers Urgently Required. APJHM. (5)2: pp. 4-6

3. ABC News. (2020). World Health Assembly formally adopts independent review into handling of coronavirus pandemic. Available from https://www.abc.net.au/news/2020-05-19/whaformally-adopts-review-into-handlingcoronavirus/12265040. ABC News Live Blog. Nick Dale. 19th May 2020.

4. Kerrissey, MJ. Edmondson, AC. What good leadership looks like during this pandemic? Harvard Business Review. April 13, 2020. Available from https://hbr.org/2020/04/what-good-leadership-lookslike-during-this-pandemic.

5. Briggs, DS. Isouard, G. (2016). The language of health reform and health management: critical issues in the management of health systems. Asia Pacific Journal of Health Management. (11): 3. pp 38-44.

6. Briggs, DS. (2017). Challenges for health systems: Australian Perspectives. Public Administration and Policy. PAAP 20.1:06-17, 2017.

7. Productivity Commission. (2017). Report on Government Services, Public Hospitals. Australian Government Productivity Commission. Available from http://www.pc.gov.au/research/ongoing/reportongovernment-services/2016/health/publichospitals/rogs-2016-volumee-chapter 1 1.pdf

8. Dawson, A. (2020). How Covid_19 made me more Australian. Available from

https://pursuit.unimelb.edu.au/articles/how-covid-19made-me-more-australian. This article was first published on Pursuit.

9. EveryAgeCounts. (2020). Available from https://www.everyagecounts.org.au/about.

10. Briggs, DS. (2008). SHAPE Declaration on the organisation and management of health services: a call for informed public debate. Asia Pacific Journal of Health Management 3(2): pp.10-13. 